\title{
Psychologic Treatment of Depression Compared With Pharmacotherapy and Combined Treatment in Primary Care: A Network Meta-Analysis
}

Pim Cuijpers, $P b D^{1}$

Mattbijs Oud, $M A^{2}$

Eirini Karyotaki, $P b D^{1}$

Hisasbi Noma, $P b D^{3}$

Soledad Quero, $\mathrm{PbD}^{4,5}$

Andrea Cipriani, $M D, P b D^{6,7}$

Bruce Arroll, $P b D^{8}$

Tosbi A. Furukawa, MD, $P b D^{9}$

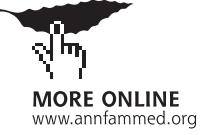

Conflicts of interest: P.C. receives allowances for his memberships on the Board of Directors of Mind, Fonds Psychische Gezondheid, and Korrelatie, and for being Chair of the PACO Committee of the Raad voor Civiel-militaire Zorg en Onderzoek of the Dutch Ministry of Defense, and for being Deputy Editor of Depression and Anxiety and Associate Editor of Psychological Bulletin. He also receives royalties for books be bas authored or coauthored and for occasional workshops and invited addresses. He received grants from the European Union (FP7 and H2O2O), ZonMw, and PFGV. T.A.F. reports personal fees from Mitsubishi-Tanabe, MSD, and Shionogi and a grant from Mitsubishi-Tanabe outside the submitted work, T.A.F. has a patent 2018-177688 pending. A.C. has received research and consultancy fees from INCiPiT (Italian Network for Paediatric Trials), CARIPLO Foundation, and Angelini Pharma. H.N. reports personal fees from Boebringer Ingelbeim, Kyowa Kirin, ASKA Pharmacentical, and Toyota Motor Corporation outside the submitted work. The other authors report none.

\section{CORRESPONDING AUTHOR}

Pim Cuijpers

Department of Clinical, Neuro

and Developmental Psychology

Amsterdam Public Health

Research Institute

Vrije Universiteit Amsterdam,

The Netherlands,

Van der Boechorststraat 7-9

1081 BT Amsterdam, The Netherlands

p.cuijpers@vu.nl

\begin{abstract}
PURPOSE Most patients with depression are treated by general practitioners, and most of those patients prefer psychotherapy over pharmacotherapy. No network meta-analyses have examined the effects of psychotherapy compared with pharmacotherapy, combined treatment, care as usual, and other control conditions among patients in primary care.
\end{abstract}

METHODS We conducted systematic searches of bibliographic databases to identify randomized trials comparing psychotherapy with pharmacotherapy, combined treatment, care as usual, waitlist, and pill placebo. The main outcome was treatment response ( $50 \%$ improvement of depressive symptoms from baseline to end point).

RESULTS A total of 58 studies with 9,301 patients were included. Both psychotherapy and pharmacotherapy were significantly more effective than care as usual (relative risk $[R R]$ for response $=1.60 ; 95 \% \mathrm{Cl}, 1.40-1.83$ and $\mathrm{RR}=1.65$; $95 \% \mathrm{Cl}, 1.35-2.03$, respectively) and waitlist ( $\mathrm{RR}=2.35 ; 95 \% \mathrm{Cl}, 1.57-3.51$ and $\mathrm{RR}=2.43 ; 95 \% \mathrm{Cl}, 1.57-3.74$, respectively) control groups. We found no significant differences between psychotherapy and pharmacotherapy (RR $=1.03 ; 95 \%$ $\mathrm{Cl}, 0.88-1.22)$. The effects were significantly greater for combined treatment compared with psychotherapy alone ( $R R=1.35 ; 95 \% \mathrm{Cl}, 1.00-1.81)$. The difference between combined treatment and pharmacotherapy became significant when limited to studies with low risk of bias and studies limited to cognitive behavior therapy.

CONCLUSIONS Psychotherapy is likely effective for the treatment of depression when compared with care as usual or waitlist, with effects comparable to those of pharmacotherapy. Combined treatment might be better than either psychotherapy or pharmacotherapy alone.

Ann Fam Med 2021;19:262-270. https://doi.org/10.1370/afm.2676.

\section{INTRODUCTION}

$\mathrm{H}$ undreds of randomized trials have examined the effects of pharmacologic and psychologic treatments for depression. ${ }^{1,2}$ However, the majority of depressed patients are treated in primary care, and relatively few of have focused on primary care. ${ }^{3,4}$ The results for treatments across varying settings might not be valid for patients in primary care.

Antidepressant drugs and psychotherapy have small, positive effects on depression. Both treatment modalities have comparable effects in primary care. ${ }^{5}$ For the longer term, psychotherapy might have better outcomes than pharmacotherapy. ${ }^{6,7}$ Many general practitioners (GPs) are inclined to prescribe mainly antidepressant drugs, ${ }^{8}$ whereas $75 \%$ of patients prefer psychotherapy. ${ }^{9-11}$

Conventional meta-analyses have shown that psychotherapy is effective for patients in primary care. ${ }^{12-18} \mathrm{~A}$ network meta-analysis (NMA) of psychotherapy for patients in primary care found few significant differences between types of therapy. ${ }^{12}$ This is in line with meta-analyses across 
treatment settings, which consistently showed no relevant differences between therapies. 2,19

An NMA of treatments for depression in primary care has been conducted but focused mostly on clinical differences between types of trials in this field. ${ }^{20}$

To the best of our knowledge, no NMAs with a focus on outcomes have been conducted in which psychotherapy for patients in primary care is compared with pharmacotherapy, combined treatment, and control conditions. Network meta-analyses can compare several alternative treatments in a single analysis and are able to use direct and indirect data, thus making optimal use of all available evidence. ${ }^{20,21}$

We conducted an NMA comparing the effects of psychotherapy with those of pharmacotherapy, combined treatment, and control conditions for depression. We included studies focusing on major depression, persistent mood disorders (dysthymia), or both, as well as studies that included patients scoring high on selfrating depression scales.

\section{METHODS}

\section{Identification and Selection of Studies}

The protocol for this meta-analysis was registered at the Open Science Foundation. ${ }^{22}$ We identified studies via an existing database of randomized trials on psychotherapy for depression. ${ }^{23}$ The database is continuously updated, and every year in January searches for the prior year are conducted (from 1966 to January 1, 2019). Four bibliographic databases (PubMed, PsycInfo, Embase, Cochrane Library) were searched by combining the index and text words of depression and psychotherapy, with filters for randomized controlled trials (see Supplemental Appendix 1, https://www.Ann FamMed.org/content/19/3/262/suppl/DC1/, for full search string for PubMed). After importing the references in Endnote and removing duplicates, 2 independent researchers (E.K., P.C.) screened all records and full texts. Discrepancies were resolved via discussion.

We included studies in which a psychologic treatment for adult patients (aged $\geq 18$ years) with depression who were recruited from primary care was compared with antidepressant medication, combined treatment, care as usual (care usually delivered by GPs), waitlist, or pill placebo. Depression could be established with a diagnostic interview or a score greater than a cutoff point on a self-report measure. We included any type of psychotherapy. ${ }^{24,25}$ Therapy could be applied in individual, group, telephonesupported, or guided self-help (Internet-based or not) format because these formats have been found to have comparable effects across different settings. ${ }^{26}$ Unguided interventions without human support were excluded because these have been found to be less effective. ${ }^{26}$ Comorbid mental or somatic disorders were not excluded. ${ }^{27}$ We included studies published in English, Spanish, Dutch, or German.

When a study contained $\geq 2$ arms to be included in the same node (eg, when a study compared 2 types of psychotherapy with 1 pharmacotherapy condition), we considered them as separate comparisons. These were subdivided appropriately to avoid double counting.

\section{Risk of Bias and Data Extraction}

Risk of bias (RoB) was assessed using the following 4 criteria of the Cochrane tool ${ }^{28}$ : adequate generation of allocation sequence, concealment of allocation to conditions, prevention of knowledge of the allocated intervention (masking of assessors), and dealing with incomplete outcome data (this was assessed as positive when intention-to-treat analyses were conducted). Items were rated by 2 independent assessors (P.C., E.K.), and disagreements were resolved via discussion. Studies were judged as low RoB when all 4 items were rated as positive.

Pharmacotherapy studies were assessed regarding the use of therapeutic dose and titration schedule (ie, therapeutic dose achieved within 3 weeks). Pharmacotherapy was deemed adequate if both criteria were met. Psychotherapy studies were assessed on (1) use of a treatment manual, (2) use of specially trained therapists, and (3) verification of treatment integrity. ${ }^{29,30} \mathrm{We}$ also coded participant and intervention characteristics (Supplemental Appendix 2, https://www.AnnFamMed. org/content/19/3/262/supp1/DC1/).

\section{Outcome Measures}

Treatment response (50\% decrease in depressive symptomatology) was selected as the primary outcome. When not reported, we imputed response rate using a validated method using mean depression score at baseline and mean, SD, and number of patients at post test. ${ }^{31}$ Patients randomized but not included in the analyses of responders were assumed to be nonresponders and were included in the analyses according to the intention-to-treat principle. The time point for the primary outcome was the end of psychotherapy. When multiple scales were used, we selected a single instrument using an algorithm prioritizing clinicianrated instruments over self-rated instruments and according to how often the instruments (Hamilton Depression Rating Scale, Montgomery-Åsberg Depression Rating Scale, another clinician-rated instrument, Beck Depression Inventory I or II, another self-rated instrument) are used in depression trials.

Remission was defined as a depression score less than a specific cut-off on a validated rating scale. The 
standardized mean difference (SMD) between each of the contrasts was based on mean, SD, and number of patients for the conditions at post test. Acceptability of treatment was operationalized as study dropout for any reason.

\section{Pairwise Meta-Analyses}

We conducted pairwise meta-analyses for all comparisons using a random effects model. To quantify heterogeneity, we calculated the $I^{2}$ statistic using the noncentral $\chi^{2}$-based approach within the heterogi module for Stata (StataCorp LLC). ${ }^{32}$ We tested for small-study effects with the Egger test. ${ }^{33}$

\section{Network Meta-Analyses}

Comparative effectiveness was evaluated using NMA methodology. First, we summarized the geometry of the network of evidence using network plots for response. ${ }^{34}$ We then conducted contrast-based NMA to assess comparative efficacy and acceptability. ${ }^{35}$ Random effect models were used in all analyses. ${ }^{36}$ Relative risks (RRs) and SMDs were reported with 95\% CIs. The ranking of treatments was estimated with the surface under the cumulative ranking curve, based on the estimated multivariate random effects models. ${ }^{34}$

The transitivity assumption was examined via a table of study characteristics. We verified if potential effect modifiers were similarly distributed across the comparisons in the network. We checked the consistency of the network using the local test of inconsistency (with the loop-specific approach, which estimates in each triangular and quadrangular loop whether the direct and indirect effects are consistent $)^{37}$ and the global test of inconsistency (the design-by-treatment interaction test). ${ }^{38}$ Potential influences of small-study effects were examined with metaregression analyses, adjusting the study-specific variance as a covariate. ${ }^{39}$

\section{Heterogeneity, Metaregression, and Sensitivity Analyses}

We evaluated the heterogeneity in the network with $\tau^{2}$ compared with empirically derived values. ${ }^{40,41}$ To explore possible sources of heterogeneity, we conducted a multivariate metaregression analysis with the characteristics that were also used to examine transitivity. We conducted sensitivity analyses in which we limited the analysis to (1) studies with low RoB, (2) studies of cognitive behavior therapy (CBT) alone, or (3) studies with pill placebo excluded (in these studies, patients receiving drugs are blinded, and patients in psychotherapy are not). ${ }^{42}$

The main analyses were conducted with Stata/SE 14.2 for Mac (StataCorp LLC). The metaregression analyses examining small-sample bias were conducted with OpenBUGS-3.2.3 (OpenBUGS Foundation). In addition, the main analyses examining the effect sizes of all comparisons for response and acceptability were conducted independently by one of the authors (H.N.) with the Bayesian framework using the gemtc package in $\mathrm{R}$ ( $\mathrm{R}$ Foundation). The analyses were conducted in November 2019.

\section{RESULTS}

\section{Selection and Inclusion of Studies}

We examined 21,976 abstracts (16,701 after removal of duplicates) and retrieved 2,553 full-text papers. The Preferred Reporting Items for Systematic Reviews and Meta-Analyses flowchart describing the inclusion process $^{43}$ is presented in Supplemental Appendix 3 (https:// www.AnnFamMed.org/content/19/3/262/suppl/DC1/). A total of 58 studies met the inclusion criteria $(9,301$ patients). Selected characteristics of the included studies are summarized in Supplemental Appendix 2, and references in Supplemental Appendix 4 (https://www. AnnFamMed.org/content/19/3/262/suppl/DC1/). In 4 studies, 2 types of psychotherapy were examined as separate arms (including 1 in which the treatment was provided by either a nurse or a GP). In total, $62 \mathrm{com}$ parisons were available for the NMA (psychotherapy: 56, pharmacotherapy: 16 ; combined: 5 ; care as usual [CAU]: 39; waitlist: 6 ; pill placebo: 3 ).

\section{Characteristics of Included Studies}

The aggregated characteristics of the included studies are presented in Table 1. In 19 studies, patients were recruited via systematic screening. Twelve trials were aimed at specific target groups, 32 used CBT as therapy, 39 used an individual treatment format, and the therapy was adequate in 28. A selective serotonin reuptake inhibitor was applied in 7 of the 16 studies examining pharmacotherapy, and in 9 of these the pharmacotherapy was adequate.

A total of 44 studies reported an adequate sequence generation, 44 reported allocation to conditions by an independent party, 25 reported masking of outcome assessors, and 30 used only self-report outcomes. In 44 studies, intention-to-treat analyses were conducted. A total of 28 studies met all 4 RoB criteria, 14 met 3 criteria, and 20 met $\leq 2$ criteria.

\section{Pairwise Meta-Analyses}

Supplemental Appendix 5 (https://www.AnnFamMed. org/content/19/3/262/suppl/DC1/) shows the results of the pairwise meta-analyses. Forest plots for response rates with $\geq 5$ comparisons are shown in Supplemental Appendices 6-9 (https://www.AnnFamMed.org/ 
content/19/3/262/suppl/DC1/). Heterogeneity was low to moderate for most comparisons. For the comparisons on response, only heterogeneity of combined treatment vs pharmacotherapy was high (84\%). The Egger test was significant only for psychotherapy vs care as usual $(P=.01)$ and for psychotherapy vs waitlist $(P=.01)$.

\section{Network Plot}

The network for response is presented graphically in Figure 1. The number of studies for each comparison is listed in Supplemental Appendix 5. The most examined nodes were psychotherapy, CAU, and pharmacotherapy. A small number of comparisons included combined treatment, pill placebo, or waitlist. Several nodes were not well connected to the network. Waitlist had a small connection to psychotherapy and none to any other node. The control conditions were not connected to each other, and combined treatment was not connected to any of the control conditions. The contribution plot, showing the percentages of contributions from the direct comparisons separately for the mixed and indirect estimates, is presented in Supplemental Appendix 10 (https://www.AnnFamMed.org/ content/19/3/262/suppl/DC1/).

\section{Network Meta-Analysis}

The main results of the NMA for response, remission, acceptability, and SMD are presented in Table 2. The outcomes are presented graphically in Figure 2. No significant difference was found between psychotherapy and pharmacotherapy for response $(\mathrm{RR}=1.03 ; 95 \% \mathrm{CI}, 0.88-1.22)$. Combined treatment was significantly more effective than psychotherapy $(\mathrm{RR}=1.35 ; 95 \% \mathrm{CI}$, 1.00-1.81) but not than pharmacotherapy ( $\mathrm{RR}=1.30 ; 95 \% \mathrm{CI}, 0.98$ 1.73), although this might have been caused by low power. Psychotherapy, pharmacotherapy, and combined treatment were all more Effect Modifiers effective than CAU $(R R s=1.60,1.65,2.15$, respectively) and waitlist ( $R R s=2.35,2.43,3.16$, respectively). The number of studies including pill placebo was too small to result in meaningful outcomes.

The outcomes for remission were comparable to those for response, with the exception that combined treatment was not significantly different from psychotherapy. The SMDs for CAU ranged from 0.70 (95\%
Table 1. Description of Included Studies and Distribution of Potential

\begin{tabular}{|c|c|c|c|c|c|}
\hline & $\begin{array}{l}\text { All } \\
\text { Studies } \\
\text { n }(\%)\end{array}$ & $\begin{array}{l}\text { Psy vs } \\
\text { CAU } \\
\text { n (\%) }\end{array}$ & $\begin{array}{c}\text { Psy vs Pha } \\
\text { n (\%) }\end{array}$ & $\begin{array}{l}\text { Pha vs } \\
\text { Comb } \\
\text { n }(\%)\end{array}$ & $\begin{array}{c}\text { Psy vs WL } \\
\text { n }(\%)\end{array}$ \\
\hline \multicolumn{6}{|l|}{ Patients } \\
\hline \multicolumn{6}{|l|}{ Screening } \\
\hline Yes & 19 (30.6) & $12(30.8)$ & $7(41.2)$ & $3(60.0)$ & $0(0)$ \\
\hline No & $43(69.4)$ & $27(69.2)$ & $10(58.8)$ & $2(40.0)$ & $6(100.0)$ \\
\hline \multicolumn{6}{|l|}{ Target group } \\
\hline Adults & $50(80.6)$ & $31(79.5)$ & $13(76.5)$ & $4(80.0)$ & $6(100.0)$ \\
\hline Specific groupb & $12(19.4)$ & $8(20.5)$ & $4(23.5)$ & $1(20.0)$ & $0(0)$ \\
\hline \multicolumn{6}{|l|}{ Psychotherapy } \\
\hline \multicolumn{6}{|l|}{ Type } \\
\hline CBT & $32(51.6)$ & $22(56.4)$ & $3(17.6)$ & $2(40.0)$ & $5(83.3)$ \\
\hline IPT & $6(9.7)$ & $3(7.7)$ & $4(23.5)$ & $1(20.0)$ & $0(0)$ \\
\hline PST & $8(12.9)$ & $2(5.1)$ & $6(35.3)$ & $1(20.0)$ & $0(0)$ \\
\hline Supportive & $5(8.1)$ & $3(7.7)$ & $3(17.6)$ & $0(0)$ & $0(0)$ \\
\hline Other & $11(17.7)$ & $9(23.1)$ & $1(5.9)$ & $1(20.0)$ & $1(16.7)$ \\
\hline \multicolumn{6}{|l|}{ Format } \\
\hline Individual & 39 (62.9) & $24(61.5)$ & $13(76.5)$ & $4(80.0)$ & $2(33.3)$ \\
\hline Group/GSH mixed & $23(37.1)$ & $15(38.5)$ & $4(23.5)$ & $1(20.0)$ & $4(66.7)$ \\
\hline Adequate & $28(45.2)$ & $22(56.4)$ & $4(23.5)$ & $3(60.0)$ & $1(16.7)$ \\
\hline \multicolumn{6}{|l|}{ Pharmacotherapy } \\
\hline \multicolumn{6}{|l|}{ Type } \\
\hline SSRI & $7(11.3)$ & $0(0)$ & $6(35.3)$ & $2(40.0)$ & $0(0)$ \\
\hline Other & $9(14.5)$ & $0(0)$ & $7(41.2)$ & $3(60.0)$ & $0(0)$ \\
\hline None & $46(74.2)$ & $0(0)$ & $4(23.5)$ & $0(0)$ & $0(0)$ \\
\hline Adequate & $9(56.3)^{c}$ & $0(0)$ & $8(47.1)$ & $2(40.0)$ & $0(0)$ \\
\hline \multicolumn{6}{|c|}{ General study characteristics } \\
\hline \multicolumn{6}{|l|}{ Country } \\
\hline North America & 9 (14.5) & $6(15.4)$ & $4(23.5)$ & $1(20.0)$ & $0(0)$ \\
\hline Europe & $40(64.5)$ & $24(61.5)$ & $11(64.7)$ & $4(80.0)$ & $6(100.0)$ \\
\hline Other & $13(21.0)$ & $9(23.1)$ & $2(11.8)$ & $0(0)$ & $0(0)$ \\
\hline \multicolumn{6}{|l|}{ Risk of bias } \\
\hline Low & $28(45.2)$ & $15(38.5)$ & $8(47.1)$ & $4(80.0)$ & $2(33.3)$ \\
\hline At least some & $34(54.8)$ & $24(61.5)$ & $9(52.9)$ & $1(20.0)$ & $4(67.7)$ \\
\hline Total & $62(100.0)$ & $39(100.0)$ & $17(100.0)$ & $5(100.0)$ & $6(100.0)$ \\
\hline \multicolumn{6}{|c|}{$\begin{array}{l}\mathrm{CAU}=\text { care as usual; } \mathrm{CBT}=\text { cognitive behavior therapy; } \mathrm{Comb}=\text { combined treatment; } \mathrm{GSH}=\text { guided self-help; } \\
\text { IPT = interpersonal psychotherapy; Pha = pharmacotherapy; } \mathrm{PST}=\text { problem-solving therapy; Psy = psycho- } \\
\text { therapy; SSRI = selective serotonin reuptake inhibitor; } \mathrm{WL}=\text { waitlist. }\end{array}$} \\
\hline \multicolumn{6}{|c|}{$\begin{array}{l}\text { a Includes all } 62 \text { comparisons. } \\
\text { b Specific groups refer to older adults (García-Peña, 2015; Joling, 2011; Laidlaw, 2008; Serfaty, 2009; Scogin, } \\
\text { 2018; Williams, 2000), }{ }^{44-49} \text { women with postpartum depression (Chibanda, 2014; Sharp, 2010), }{ }^{50-51} \text { minorities } \\
\text { (Dwight-Johnson, 2011; Gater, 2010), }{ }^{52-53} \text { and patients with comorbid headache/migraine. }{ }^{54} \text { See Supplemental } \\
\text { Appendix } 4 \text { for complete references for all studies. } \\
\text { ' This is } 56.3 \% \text { of the } 16 \text { studies that included pharmacotherapy. }\end{array}$} \\
\hline
\end{tabular}




\section{Figure 1. Network plot.}

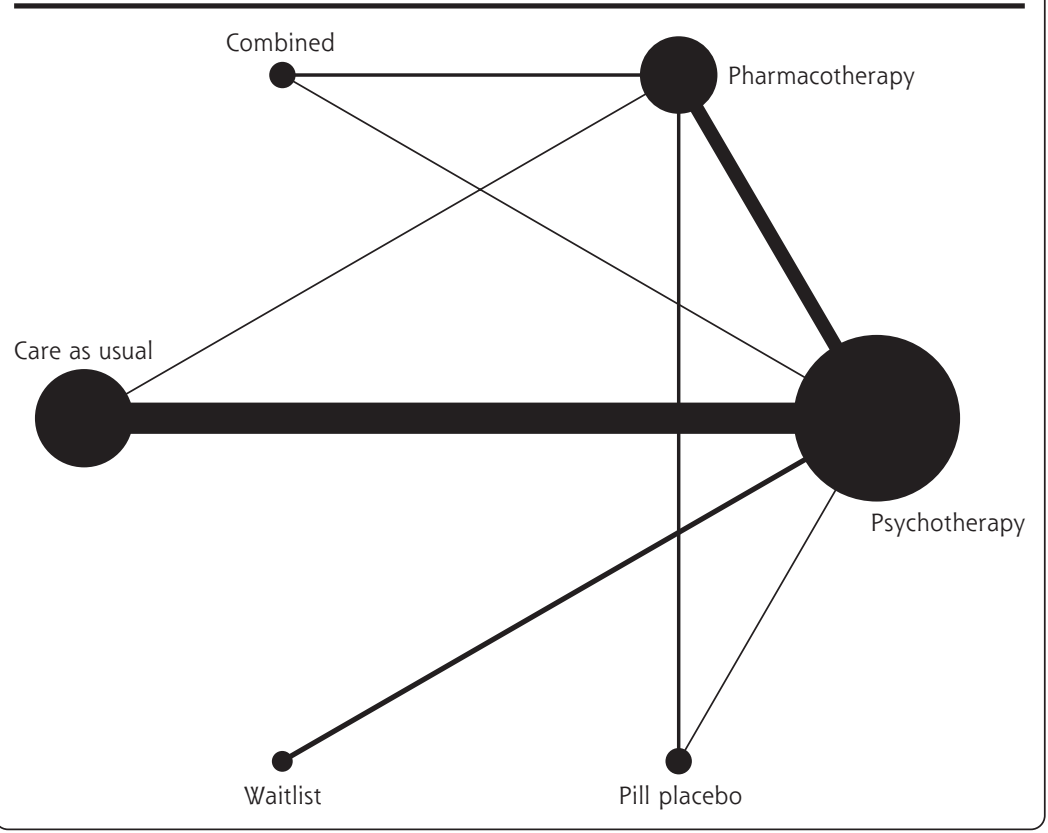

Table 1. Visual inspection of the distribution across comparisons indicated that the potential effect modifiers were similarly distributed across the comparisons. This suggested no significant evidence against the transitivity assumption. However, this must be considered with caution because of the small sample sizes in some cells.

Examination of consistency with the loop-specific approach (Supplemental Appendix 11, https://www. AnnFamMed.org/content/19/3/262/ suppl/DC1/) indicated that no loop was significantly inconsistent. However, this cannot be considered as evidence for the absence of inconsistency because of the small or zero number of comparisons in several loops. The design-bytreatment interaction model did not indicate global inconsistency in the

CI, 0.35-1.05) for combined treatment to 0.44 (95\% CI, 0.31-0.57) for psychotherapy and 0.41 (95\% CI, 0.18-0.64) for pharmacotherapy. None of the outcomes for acceptability were significant.

The distribution of potential effect modifiers for the 4 comparisons with $\geq 5$ studies is presented in network $\left(\chi^{2}=8.02 ; \mathrm{df}=5 ; P\right.$ for the null hypothesis of consistency in the network $=.16$ ).

\section{Ranking of Treatments}

The results for surface under the cumulative ranking curve are summarized in Table 3 . Combined treatment

Table 2. Response, Remission, SMD, and Acceptability for Psychotherapy, Pharmacotherapy, and Combined Treatment Compared With Each Other and Control Conditions (CAU, Waitlist, Placebo) ${ }^{a}$

\begin{tabular}{|c|c|c|c|c|c|c|}
\hline \multicolumn{7}{|c|}{ Acceptability } \\
\hline \multirow{6}{*}{ 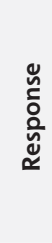 } & Combined & $1.11(0.65-1.90)$ & $1.00(0.57-1.76)$ & $0.81(0.42-1.58)$ & $0.93(0.52-1.67)$ & $0.84(0.41-1.72)$ \\
\hline & $1.30(0.98-1.73)$ & Pharmacotherapy & $0.90(0.69-1.18)$ & $0.73(0.48-1.11)$ & $0.84(0.61-1.15)$ & $0.75(0.44-1.28)$ \\
\hline & $1.35(1.00-1.81)$ & $1.03(0.88-1.22)$ & Psychotherapy & $0.81(0.53-1.25)$ & $0.93(0.78-1.10)$ & $0.83(0.53-1.31)$ \\
\hline & $1.65(1.10-2.46)$ & $1.26(0.94-1.71)$ & $1.22(0.90-1.66)$ & Pill placebo & $1.15(0.72-1.82)$ & $1.03(0.55-1.93)$ \\
\hline & $2.15(1.56-2.97)$ & $1.65(1.35-2.03)$ & $1.60(1.40-1.83)$ & $1.31(0.94-1.81)$ & CAU & $0.90(0.55-1.45)$ \\
\hline & $3.16(1.91-5.21)$ & $2.43(1.57-3.74)$ & $2.35(1.57-3.51)$ & $1.92(1.16-3.17)$ & $1.47(0.96-2.23)$ & Waitlist \\
\hline \multicolumn{7}{|c|}{ Standardized Mean Difference } \\
\hline \multirow{5}{*}{ 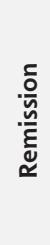 } & Combined & $0.29(-0.03$ to 0.60$)$ & $0.26(-0.07$ to 0.59$)$ & $0.54(0.06-1.02)$ & $0.70(0.35-1.05)$ & $1.13(0.64-1.61)$ \\
\hline & $1.25(0.77-2.04)$ & Pharmacotherapy & $-0.03(-0.22$ to 0.17$)$ & $0.25(-0.13$ to 0.63$)$ & $0.41(0.18-0.64)$ & $0.84(0.44-1.24)$ \\
\hline & $1.35(0.81-2.26)$ & $1.08(0.87-1.34)$ & Psychotherapy & $0.28(-0.10$ to 0.66$)$ & $0.44(0.31-0.57)$ & $0.86(0.51-1.22)$ \\
\hline & $2.09(1.22-3.58)$ & $1.67(1.28-2.18)$ & $1.55(1.29-1.85)$ & $1.20(0.79$ to 1.82$)$ & CAU & $0.43(0.05-0.80)$ \\
\hline & $3.26(1.57-6.77)$ & $2.60(1.48-4.58)$ & $2.41(1.43-4.06)$ & $1.87(0.98$ to 3.56$)$ & $1.56(0.90-2.70)$ & Waitlist \\
\hline \multicolumn{7}{|c|}{$\mathrm{CAU}=$ care as usual; $\mathrm{RR}=$ relative risk $; \mathrm{SMD}=$ standardized mean difference. } \\
\hline \multicolumn{7}{|c|}{ Note: Data are shown as RR ( $95 \% \mathrm{CI}$ ) (upper panel and lower left of lower panel) or SMD ( $95 \% \mathrm{CI}$ ) (upper right of lower panel). } \\
\hline \multicolumn{7}{|c|}{$\begin{array}{l}\text { In the lower left triangle of the upper part of the table, RR }>1 \text { means that the column-defining intervention increases the event of interest compared with the row- } \\
\text { defining intervention. Therefore, the former is more efficacious than the latter. In the upper right triangle, RR }>1 \text { means that the row-defining intervention increases } \\
\text { the event of interest compared with the column-defining intervention. Therefore, the former is less acceptable than the latter. In the lower left triangle of the lower } \\
\text { portion of the table, RR }>1 \text { means that the column-defining intervention increases the event of interest compared with the row-defining intervention. In the upper } \\
\text { right triangle, SMD }>0 \text { means that the row-defining intervention is more effective compared to the column-defining intervention. }\end{array}$} \\
\hline
\end{tabular}


Figure 2. Ranked forest plots.

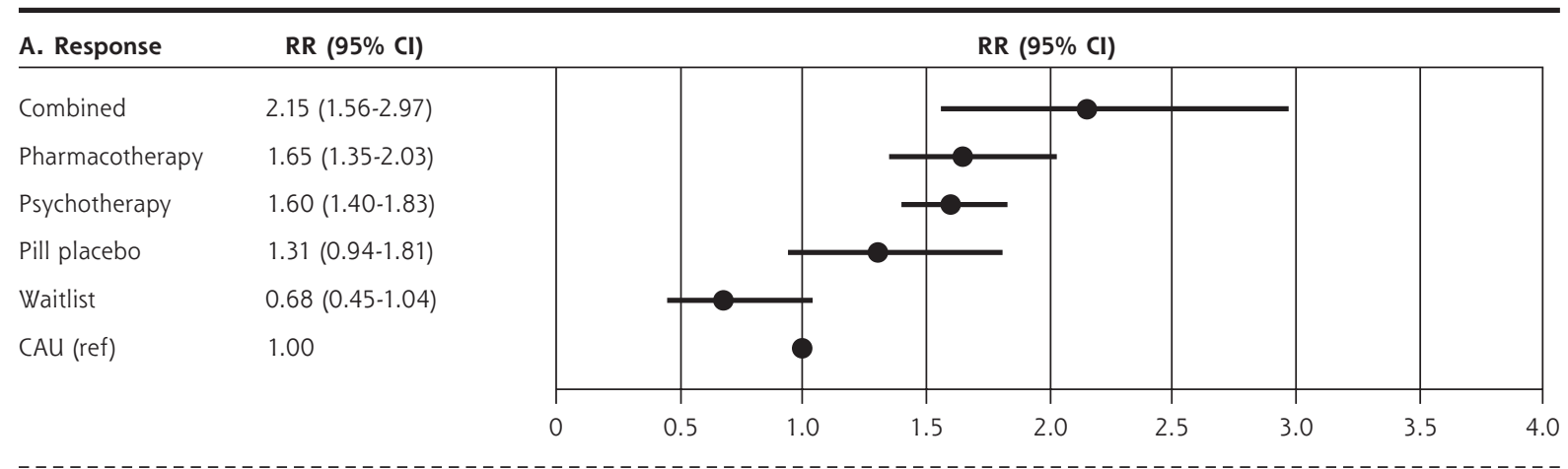

B. Remission

RR $(95 \% \mathrm{Cl})$

RR $(95 \% \mathrm{Cl})$

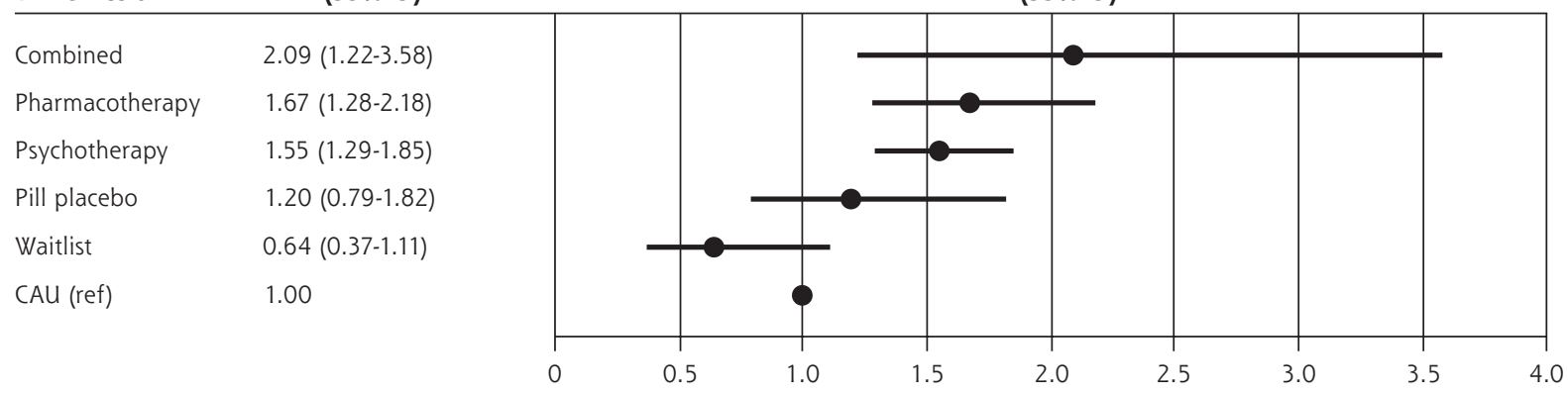

C. SMD

SMD $(95 \% \mathrm{Cl})$

SMD $(95 \% \mathrm{Cl})$

Combined

0.70 (0.35-1.05)

Pharmacotherapy

$0.41(0.18-0.64)$

Psychotherapy

$0.44(0.31-0.57)$

Pill placebo

$0.16(-0.24$ to 0.56$)$

Waitlist

$-0.43(-0.80$ to -0.05$)$

CAU (ref)

0

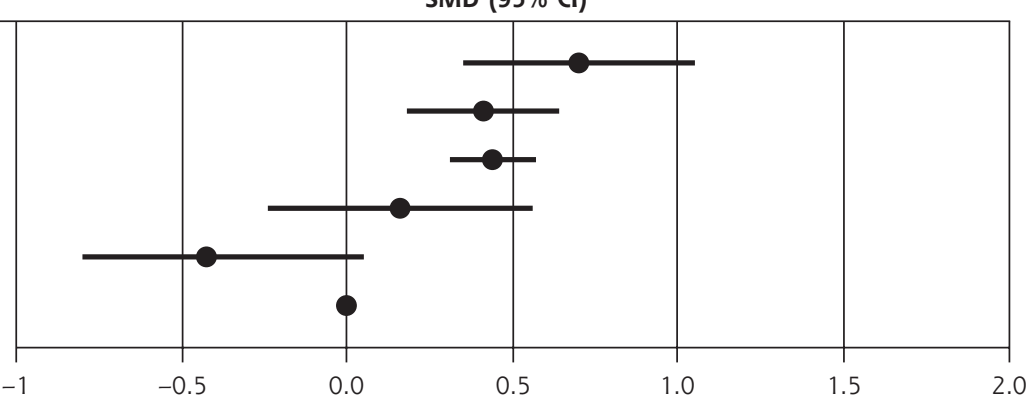

D. Acceptability

\section{RR $(95 \% \mathrm{Cl})$}

Combined

Pharmacotherapy

Psychotherapy

Pill placebo

Waitlist

CAU (ref)

$$
1.00
$$

\section{$0.93(0.52-1.67)$}

$0.84(0.61-1.15)$

$0.93(0.78-1.10)$

1.15 (0.72-1.82)

$1.11(0.69-1.82)$

1.00
RR $(95 \% \mathrm{Cl})$

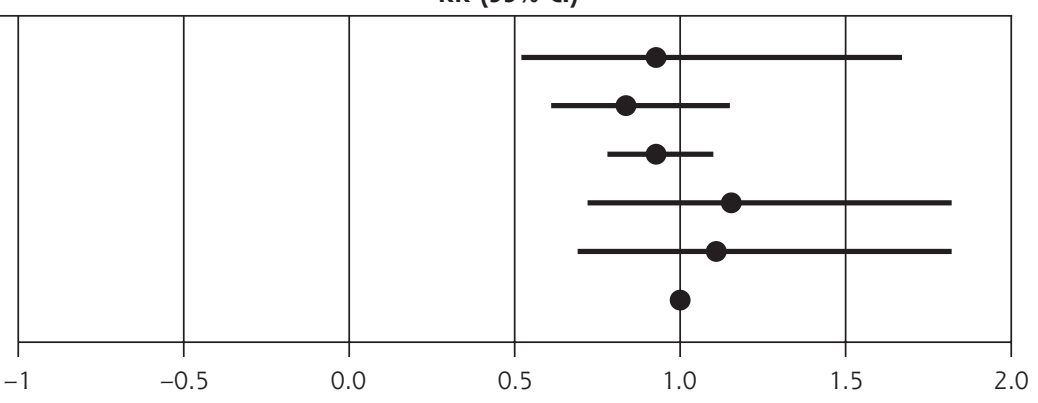

2.0

$\mathrm{CAU}=$ care as usual; $\mathrm{RR}=$ relative risk; $\mathrm{SMD}=$ standardized mean difference.

ranked clearly best for response, remission, and SMD. There were no large differences between psychotherapy and pharmacotherapy for response, remission, or SMD. No clear directions were found for acceptability.

\section{Heterogeneity and Metaregression}

The common $\tau^{2}$ estimates were 0.06 for response, 0.12 for remission, 0.10 for SMD, and 0.09 for acceptability. Compared with the empirically predicted distribution 
for semiobjective outcomes in drug vs placebo comparisons (median 0.049; 95\% CI, 0.001$1.83){ }^{41}$ the heterogeneity variance estimates would be moderate.

The results of the multivariate metaregression analysis that was conducted to examine possible sources of heterogeneity are shown in Supplemental Appendix 12 (https://www. AnnFamMed.org/content/19/3/262/suppl/ $\mathrm{DC} 1 /$ ). For several comparisons, a considerable number of outcomes were not available because there were not enough studies in the comparisons or because of collinearity. Only 1 predictor (screening vs other recruitment of patients) was found to be significant in the comparison between psychotherapy and CAU $(P=.03)$.

\section{Sensitivity Analyses and Follow-Up}

The results of the sensitivity analyses in which we included only studies with low RoB (Supplemental Appendix 13, https://www.AnnFamMed.org/ content/19/3/262/suppl/DC1/) resulted in outcomes comparable to the main analyses. The only exception was that the difference between psychotherapy and combined treatment, as well as the difference between pharmacotherapy and combined treatment, was now significant. In the analyses in which we included only trials on CBT (Supplemental Appendix 14, https:// www.AnnFamMed.org/content/19/3/262/suppl/DC1/), we also found that combined treatment was significantly more effective than either CBT or pharmacotherapy alone. The results of the other sensitivity analyses that were conducted are shown in Supplemental Appendices 15-19 (https://www.AnnFamMed.org/ content/19/3/262/suppl/DC1/). Overall, these analyses supported the main findings of the study.

A total of 27 studies reported outcomes at $\geq 6$ months follow-up, but the follow-up periods differed considerably, and because of the small number of studies for each of the different follow-up periods, we decided not to analyze those data.

\section{DISCUSSION}

In the present NMA, we found that combined treatment, psychotherapy, and pharmacotherapy were clearly more effective than CAU and waitlist conditions. We found no statistically significant differences between psychotherapy and pharmacotherapy. The magnitude of the effect was greater for combined treatment compared with psychotherapy and pharmacotherapy alone, although this was not significant in all analyses. We found no differences in acceptability between any of the conditions. Based on the evidence
Table 3. Ranking of Treatments by Surface Under the Cumulative Ranking Curve

\begin{tabular}{lcccc}
\hline & Response & Remission & SMD & Acceptability \\
\hline Combined & 98.7 & 92.9 & 97.7 & 56.9 \\
Pharmacotherapy & 72.5 & 78.1 & 66.5 & 81.6 \\
Psychotherapy & 65.2 & 65.2 & 71.8 & 62.8 \\
Placebo & 42.3 & 39.4 & 39.3 & 25.8 \\
Care as usual & 20.4 & 22.8 & 24.1 & 42.7 \\
Waitlist & 0.8 & 1.7 & 0.6 & 30.2 \\
\hline SMD = standardized mean difference. & & & \\
\hline
\end{tabular}

currently available, the present meta-analysis is the first to show these results in primary care.

Our present results are generally in line with a broader meta-analysis of trials across different settings. ${ }^{55}$ In that study, the effects of combined treatment were found to be superior to psychotherapy or pharmacotherapy alone, whereas those of psychotherapy and pharmacotherapy were comparable..$^{55} \mathrm{In}$ the present meta-analysis, combined treatment was not superior in all analyses; this might be related to the smaller number of trials and statistical power or to differences in the primary care populations. The broader meta-analysis also found that acceptability of psychotherapy and combined treatment were greater than that of pharmacotherapy. ${ }^{55}$ The fact that this was not supported in the present study might, again, be related to lower power or to differences in the populations. Although the findings are not unique to primary care, they do indicate that combined treatment has the best effects and that pharmacotherapy and psychotherapy have comparable effects.

Several studies included in the present NMA focused on patients with moderate to severe depression, whereas patients in primary care usually suffer from mild to moderate depression. It is also assumed that antidepressant drugs work better for more severe depression. ${ }^{56}$ The inclusion of these studies might therefore have resulted in an overestimation of the effects of pharmacotherapy in the present NMA.

There are several limitations to the present study. First, RoB was considerable in many studies, and publication bias was suspected for some comparisons. Second, waitlist was compared with psychotherapy only and did not form any closed loop therefore, only indirect evidence was available. In addition, insufficient numbers of studies were available on long-term effects. Furthermore, most studies included mixed populations of patients with major depression and dysthymia, and outcomes might differ for those populations. Finally, previous research has indicated that there might be differences in efficacy and acceptability of specific 
types of $\operatorname{drugs}_{i}{ }^{1}$ we merged all antidepressants into a single node.

Despite these limitations, we can conclude that psychotherapy and pharmacotherapy appear to be similarly effective for the treatment of depression compared with CAU or waitlist and that the effects of combined treatment might be superior to psychotherapy or pharmacotherapy alone. Treatments in primary care must be organized so as to accommodate any of these treatments in response to patients' preferences and values.

\section{To read or post commentaries in response to this article, go to https://www.AnnFamMed.org/content/19/3/262/tab-e-letters.}

Key words: depression; major depression; primary care; psychotherapy; cognitive behavior therapy; network meta-analysis

Submitted December 6, 2019; submitted, revised, October 30, 2020; accepted November 11, 2020.

Author affiliations: Department of Clinical, Neuro and Developmental Psychology, Amsterdam Public Health Research Institute, Vrije Universiteit Amsterdam, The Netherlands (P.C., E.K.); Department of Treatment, Care and Reintegration, Trimbos Institute, Utrecht, The Netherlands (M.O.); Department of Data Science, The Institute of Statistical Mathematics, Tokyo, Japan (H.N.); Department of Basic and Clinical Psychology and Psychobiology, Universitat Jaume I, Castellón, Spain (S.Q.);

CIBER of Physiopathology of Obesity and Nutrition (CIBERObn), Madrid, Spain (S.Q.); Department of Psychiatry, Warneford Hospital, University of Oxford, Oxford, United Kingdom (A.C.); Oxford Health NHS Foundation Trust, Warneford Hospital, Oxford, United Kingdom (A.C.); Department of General Practice and Primary Health Care, University of Auckland, Auckland, New Zealand (B.A.); Department of Health Promotion and Human Behavior, Kyoto University Graduate School of Medicine/ School of Public Health, Kyoto, Japan (T.A.F.)

Acknowledgments: A.C. is supported by the National Institute for Health Research (NIHR) Oxford Cognitive Health Clinical Research Facility; an NIHR Research Professorship (grant RP-2017-08-ST2-006); the NIHR Oxford and Thames Valley Applied Research Collaboration; and the NIHR Oxford Health Biomedical Research Centre (grant BRC-121520005). S.Q. is supported by CIBERObn, an initiative of the ISCIII (ISCIII CB06 03/0052). The views expressed are those of the authors and not necessarily those of the UK National Health Service, the NIHR, or the UK Department of Health.

Supplemental materials: Available at https://www.AnnFamMed. org/content/19/3/262/suppl/DC1/.

\section{References}

1. Cipriani A, Furukawa TA, Salanti G, et al. Comparative efficacy and acceptability of 21 antidepressant drugs for the acute treatment of adults with major depressive disorder: a systematic review and network meta-analysis. Lancet. 2018;391(10128):1357-1366.

2. Barth J, Munder T, Gerger H, et al. Comparative efficacy of seven psychotherapeutic interventions for patients with depression: a network meta-analysis. PLoS Med. 2013;10(5):e1001454.

3. Goldberg D, Lecrubier Y. Form and frequency of mental disorders across centers. In: Ustün T, Sartorius N, eds. Mental Illness in General Health Care: An International Study. John Wiley \& Sons; 1995:323-334.

4. Bijl RV, Ravelli A. Psychiatric morbidity, service use, and need for care in the general population: results of The Netherlands Mental Health Survey and Incidence Study. Am J Public Health. 2000;90(4): 602-607.
5. Ramanuj P, Ferenchick EK, Pincus HA. Depression in primary care: part 2-management. BMJ. 2019;365:1835.

6. Karyotaki E, Smit Y, Holdt Henningsen K, et al. Combining pharmacotherapy and psychotherapy or monotherapy for major depression? A meta-analysis on the long-term effects. J Affect Disord. 2016; 194:144-152.

7. Cuijpers $P$, Hollon SD, van Straten A, Bockting C, Berking M, Andersson $G$. Does cognitive behaviour therapy have an enduring effect that is superior to keeping patients on continuation pharmacotherapy? A meta-analysis. BMJ Open. 2013;3(4):e002542.

8. Olfson M, Marcus SC. National trends in outpatient psychotherapy Am J Psychiatry. 2010;167(12):1456-1463.

9. van Schaik DJ, Klijn AF, van Hout HP, et al. Patients' preferences in the treatment of depressive disorder in primary care. Gen Hosp Psychiatry. 2004;26(3):184-189.

10. McHugh RK, Whitton SW, Peckham AD, Welge JA, Otto MW. Patient preference for psychological vs pharmacologic treatment of psychiatric disorders: a meta-analytic review. J Clin Psychiatry. 2013; 74(6):595-602.

11. Dorow M, Löbner M, Pabst A, Stein J, Riedel-Heller SG. Preferences for depression treatment including internet-based interventions: results from a large sample of primary care patients. Front Psychiatry. 2018;9:181.

12. Linde K, Rücker G, Sigterman K, et al. Comparative effectiveness of psychological treatments for depressive disorders in primary care: network meta-analysis. BMC Fam Pract. 2015;16:103.

13. Santoft F, Axelsson E, Öst LG, Hedman-Lagerlöf M, Fust J, HedmanLagerlöf E. Cognitive behaviour therapy for depression in primary care: systematic review and meta-analysis. Psychol Med. 2019;49(8): 1266-1274.

14. Stephens S, Ford E, Paudyal P, Smith H. Effectiveness of psychological interventions for postnatal depression in primary care: a metaanalysis. Ann Fam Med. 2016;14(5):463-472.

15. Twomey C, O'Reilly G, Byrne M. Effectiveness of cognitive behavioural therapy for anxiety and depression in primary care: a metaanalysis. Fam Pract. 2015;32(1):3-15.

16. Wells MJ, Owen JJ, McCray LW, et al. Computer-assisted cognitivebehavior therapy for depression in primary care: systematic review and meta-analysis. Prim Care Companion CNS Disord. 2018;20(2): 17 r02196.

17. Zhang A, Franklin C, Jing $S$, et al. The effectiveness of four empirically supported psychotherapies for primary care depression and anxiety: a systematic review and meta-analysis. J Affect Disord. 2019;245:1168-1186.

18. Zhang A, Park S, Sullivan JE, Jing S. The effectiveness of problemsolving therapy for primary care patients' depressive and/or anxiety disorders: a systematic review and meta-analysis. J Am Board Fam Med. 2018;31(1):139-150.

19. Cuijpers P, van Straten A, Andersson G, van Oppen P. Psychotherapy for depression in adults: a meta-analysis of comparative outcome studies. J Consult Clin Psychol. 2008;76(6):909-922.

20. Linde K, Rücker G, Schneider A, Kriston L. Questionable assumptions hampered interpretation of a network meta-analysis of primary care depression treatments. J Clin Epidemiol. 2016;71:86-96.

21. Mavridis D, Giannatsi M, Cipriani A, Salanti G. A primer on network meta-analysis with emphasis on mental health. Evid Based Ment Health. 2015;18(2):40-46.

22. Cuijpers P, Karyotaki E, Ciharova M, et al. Psychological treatment of depression in primary care compared with antidepressant medication, combined treatment, care as usual, placebo, and waiting list: a network meta-analysis. Published Oct 2019. Accessed Mar 2021. https://osf.io/jt9bh

23. Cuijpers $P$, Karyotaki E, Ciharova $M$, et al. A meta-analytic database of randomised trials on psychotherapies for depression. Published Jul 9, 2019. Accessed Nov 15, 2019. https://doi.org/10.17605/OSF. $10 / 82566$ 
24. Cuijpers P, Quero S, Dowrick C, Arroll B. Psychological treatment of depression in primary care: recent developments. Curr Psychiatry Rep. 2019;21(12):129.

25. Cuijpers P, Karyotaki E, de Wit L, Ebert DD. The effects of fifteen evidence-supported therapies for adult depression: a meta-analytic review. Psychother Res. 2020;30(3):279-293.

26. Cuijpers P, Noma H, Karyotaki E, Cipriani A, Furukawa T. Effectiveness and acceptability of cognitive behavior therapy delivery formats in adults with depression: a network meta-analysis. JAMA Psychiatry. 2019;76(7):700-707.

27. Cuijpers P, Karyotaki E, Reijnders M, Huibers MJH. Who benefits from psychotherapies for adult depression? A meta-analytic update of the evidence. Cogn Behav Ther. 2018;47(2):91-106.

28. Higgins JPT, Altman DG, Gøtzsche PC, et al; Cochrane Bias Methods Group; Cochrane Statistical Methods Group. The Cochrane Collaboration's tool for assessing risk of bias in randomised trials. BMJ. 2011;343:d5928.

29. Chambless DL, Hollon SD. Defining empirically supported therapies. J Consult Clin Psychol. 1998;66(1):7-18.

30. Cuijpers P, van Straten A, Bohlmeijer E, Hollon SD, Andersson G. The effects of psychotherapy for adult depression are overestimated: a meta-analysis of study quality and effect size. Psychol Med. 2010;40(2):211-223.

31. Furukawa TA, Cipriani A, Barbui C, Brambilla P, Watanabe N. Imputing response rates from means and standard deviations in metaanalyses. Int Clin Psychopharmacol. 2005;20(1):49-52.

32. Orsini N, Bottai M, Higgins J, Buchan I. Heterogi: Stata module to quantify heterogeneity in a meta-analysis. Statistical Software Components S449201. Boston College Department of Economics. Revised Jan 25, 2006. Accessed Mar 2, 2021. https://ideas.repec. org/c/boc/bocode/s449201.html

33. Egger M, Davey Smith G, Schneider M, Minder C. Bias in metaanalysis detected by a simple, graphical test. BMJ. 1997;315(7109): 629-634.

34. Hutton B, Wolfe D, Moher D, Shamseer L. Reporting guidance considerations from a statistical perspective: overview of tools to enhance the rigour of reporting of randomised trials and systematic reviews. Evid Based Ment Health. 2017;20(2):46-52.

35. Salanti G, Higgins JP, Ades AE, loannidis JP. Evaluation of networks of randomized trials. Stat Methods Med Res. 2008;17(3):279-301.

36. Salanti G. Indirect and mixed-treatment comparison, network, or multiple-treatments meta-analysis: many names, many benefits, many concerns for the next generation evidence synthesis tool. Res Synth Methods. 2012;3(2):80-97.

37. Chaimani A, Higgins JPT, Mavridis D, Spyridonos P, Salanti G. Graphical tools for network meta-analysis in STATA. PLoS One. 2013; 8(10):e76654

38. Higgins JP, Jackson D, Barrett JK, Lu G, Ades AE, White IR. Consistency and inconsistency in network meta-analysis: concepts and models for multi-arm studies. Res Synth Methods. 2012;3(2):98-110.

39. Chaimani A, Salanti G. Using network meta-analysis to evaluate the existence of small-study effects in a network of interventions. Res Synth Methods. 2012;3(2):161-176.

40. Rhodes KM, Turner RM, Higgins JP. Predictive distributions were developed for the extent of heterogeneity in meta-analyses of continuous outcome data. J Clin Epidemiol. 2015;68(1):52-60.

41. Turner RM, Davey J, Clarke MJ, Thompson SG, Higgins JP. Predicting the extent of heterogeneity in meta-analysis, using empirical data from the Cochrane Database of Systematic Reviews. Int J Epidemiol. 2012;41(3):818-827.
42. Cuijpers P, Karyotaki E, Andersson G, Li J, Mergl R, Hegerl U. The effects of blinding on the outcomes of psychotherapy and pharmacotherapy for adult depression: a meta-analysis. Eur Psychiatry. 2015;30(6):685-693.

43. Moher D, Liberati A, Tetzlaff J, Altman DG; PRISMA Group. Preferred reporting items for systematic reviews and meta-analyses: the PRISMA statement. PLoS Med. 2009;6(7):e1000097.

44. García-Peña C, Vázquez-Estupiñan F, Avalos-Pérez F, Jiménez LVR Sánchez-Garcia S, Juárez-Cedillo T. Clinical effectiveness of group cognitive-behavioural therapy for depressed older people in primary care: a randomised controlled trial. Salud Ment (Mex). 2015; 38(1):33-39.

45. Joling KJ, van Hout HP, van't Veer-Tazelaar PJ, et al. How effective is bibliotherapy for very old adults with subthreshold depression? A randomized controlled trial. Am J Geriatr Psychiatry. 2011;19(3): 256-265.

46. Laidlaw K, Davidson K, Toner H, et al. A randomised controlled trial of cognitive behaviour therapy vs treatment as usual in the treatment of mild to moderate late life depression. Int J Geriatr Psychiatry. 2008;23(8):843-850.

47. Serfaty MA, Haworth D, Blanchard M, Buszewicz M, Murad S, King $M$. Clinical effectiveness of individual cognitive behavioral therapy for depressed older people in primary care: a randomized controlled trial. Arch Gen Psychiatry. 2009;66(12):1332-1340.

48. Scogin F, Lichstein K, DiNapoli EA, et al. Effects of integrated telehealth-delivered cognitive-behavioral therapy for depression and insomnia in rural older adults. J Psychother Integr. 2018;28(3): 292-309.

49. Williams JW Jr, Barrett J, Oxman T, et al. Treatment of dysthymia and minor depression in primary care: a randomized controlled trial in older adults. JAMA. 2000;284(12):1519-1526.

50. Chibanda D, Shetty AK, Tshimanga M, Woelk G, Stranix-Chibanda L, Rusakaniko S. Group problem-solving therapy for postnatal depression among HIV-positive and HIV-negative mothers in Zimbabwe. J Int Assoc Provid AIDS Care. 2014;13(4):335-341.

51. Sharp DJ, Chew-Graham C, Tylee A, et al. A pragmatic randomised controlled trial to compare antidepressants with a community-based psychosocial intervention for the treatment of women with postnatal depression: the RESPOND trial. Health Technol Assess. 2010; 14(43):1-153.

52. Dwight-Johnson M, Aisenberg E, Golinelli D, Hong S, O'Brien M, Ludman E. Telephone-based cognitive-behavioral therapy for Latino patients living in rural areas: a randomized pilot study. Psychiatr Serv. 2011;62(8):936-942.

53. Gater R, Waheed W, Husain N, Tomenson B, Aseem S, Creed F. Social intervention for British Pakistani women with depression: randomised controlled trial. Br J Psychiatry. 2010;197(3):227-233.

54. Martin PR, Aiello R, Gilson K, Meadows G, Milgrom J, Reece J. Cognitive behavior therapy for comorbid migraine and/or tension-type headache and major depressive disorder: an exploratory randomized controlled trial. Behav Res Ther. 2015;73:8-18.

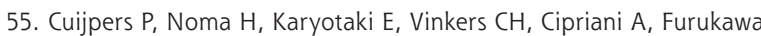
TA. A network meta-analysis of the effects of psychotherapies, pharmacotherapies and their combination in the treatment of adult depression. World Psychiatry. 2020;19(1):92-107.

56. Stone M, Kalaria S, Richardville K, Miller B. Components and trends in treatment effects in randomized placebo-controlled trials in major depressive disorder from 1979-2016. Paper presented at the American Society of Clinical Psychopharmacology; May 29-June 1, 2018; Miami, Florida. 